\section{Methicillin resistant Staphylococcus aureus}

SIR,-During the past five years a particular strain of methicillin resistant Staphylococcus aureus has been recognised as being epidemic in the Thames regions. ${ }^{12}$ This strain not only can cause serious disease in some groups of patients but has also spread within and between hospitals in spite of attempts to prevent this happening. ${ }^{134}$

Over the past 12 months we have obtained evidence that this organism is spreading outside the Thames regions, and we know of 10 instances where transfer of a patient infected or colonised with epidemic methicillin resistant $S$ aureus has resulted in the first introduction of this strain into a hospital. Transfer of the organism is often associated with patients who have undergone specialised surgical or medical procedures in the London area and may be returning to hospitals distant from the Thames regions.

The introduction of epidemic methicillin resistant $S$ aureus into a hospital is a serious event; its control may involve heavy expenditure and curtailment of clinical services, increased patient morbidity, and even mortality. Goodfield and Littlewood have recorded some of the consequences of a transfer with subsequent spread to dermatology patients. ${ }^{5}$

We strongly advise that thought should be given to the undesirability of transferring patients in this way. If such transfers are necessary patients returning from London should be isolated until they are shown to be free of the organism. Recipient hospitals should be warned by hospitals transferring patients if this methicillin resistant strain is circulating.

E $M$ COOKE R R MARPLES

Division of Hospital Infection,

Central Public Health Laboratory,

Central Public Healt
London NW9 5HT

1 Marples RR, Cooke EM. Report. Workshop on methicillin resistant Staphylococcus aureus held at the headquarters of the Public Health Laboratory Service on 8 January 1985. I Hosp Infect 1985;6:342-8.

2 Marples RR, Richardson JF, de Saxe MJ. Bacteriological characters of strains of Staphylococcus aureus submitted to reference laboratory related to methicillin resistance. $\mathcal{f} H y$ (Camb) 1986;96:217-23.

3 Ayliffe GAJ, et al. Guidelines for the control of epidemic methicillin-resistant Staphylococcus aureus. 7 Hosp Infect 1986;7:193-201.

4 Shanson DC, Johnstone D, Midgley J. Control of a hospital outbreak of methicillin-resistant Staphylococcus aureus infecoutbreak of methicillin-resistant Staphylococcus aureus infec-
tion: value of an isolation unit. $\mathcal{J}$ Hosp Infect 1985;6:285-92.

5 Goodfield MJD, Littlewood SM. Methicillin resistant Staphylococcus aureus. Lancet 1985; ii:606.

\section{The unremitting burden on carers}

SIR,-Mr Robert Anderson in his concise review of the pressures on people caring for severely disabled people living at home includes among the services required "planned respite care for their charges and free time" (10 January, p 73).

Both of these forms of help require more thoughtful planning than they have had in the past. Respite care needs to be firmly booked months in advance if the carer is to be able to have a holiday with her or his family. The disabled person will be staying in either a "home" or a hospital. If the former he or she should have the opportunity to visit the place beforehand. The staff should be aware of the different needs of short stay residents and long stay residents, whose only home the place may be. Problems of coping with short stay residents in long stay homes have been studied by Allen, ${ }^{1}$ who states, "the idea that short stay care was in any way different from long stay care was clearly one which officers and staff found difficult to cope with and it was a recurrent theme in this research."
If the respite admission is to hospital then the opportunity should be taken to reassess the clinical, functional, and social conditions of the patient and to provide a programme of rehabilitation. Dental inspection and necessary treatment should be included. Respite care should be a helpful and positive episode for the resident or patient as well as providing relief for the carer. Another aspect of the need for temporary care is the emergency admission of the disabled person during illness of the carer or other crisis in the household. Clear decisions have to be taken by health and social services managers about its provision, and general practitioners must be informed about the arrangements.

"Free time" for carers can be provided by various schemes of relief staff or visitors coming to the person's home and by the disabled person attending day centres or day hospitals. Confusion about the functions of the centres and hospitals and transport problems continue to make many of these facilities less effective than they should be. ${ }^{2-4}$ Each district health authority should be reviewing the totality of its services for severely disabled people along the lines set out in the two recent reports of the Royal College of Physicians and doing this in conjunction with the local social services department, voluntary bodies, and representatives of disabled people and their carers. ${ }^{56}$ Many aspects of respite and day care need reviewing if "community care" is to avoid overburdening the many people who are truly working or on call 24 hours a day, every day of each year, in ignorance of when their responsibilities will end and without the option of resigning or retiring.

Canterbury, Kent CT4 5AZ

MiChaEL WARREN

1 Allen I. Short-stay residential care for the elderly. London: Policy Studies Institute, 1983.

Carter J. Day services for adults. London: George Allen and Unwin, 1981.

3 Martin A, Millard PH. Day hospitals for the elderly: therapeutic or social? London: Geriatric Teaching and Research Unit, S George's Hospital, 1978 .

4 Brocklehurst JC, Tucker JS. Progress in geriatric day care. London: King Edward's Hospital Fund for London, 1980.

London: King Edward's Hospital Fund for London, 1980.
Royal College of Physicians. Physical disability in 1986 and beyond. London: Royal College of Physicians, 1986.

6 Royal College of Physicians. The young disabled adult. The use of residential homes and hospital units for the age group 16-64. London: Royal College of Physicians, 1986.

\section{Snoring as a risk factor for ischaemic heart} disease and stroke in men

SIR,-Dr Markku Koskenvo and colleagues (3 January, p 16) state that snoring is related to obstructive sleep apnoea and that these patients may develop hypoxaemia and hypercapnia, to gether with increased pulmonary and systemic arterial pressure. They later speculate that low oxygen saturation has an unfavourable effect on the activity of lipoprotein receptors, leading to increased serum low density lipoprotein concentrations; the role of thrombocyte aggregation and coronary artery spasm in sleep apnoea is also unclear. At no point do they mention the effect of hypoxia on the haemoglobin concentration or whether there was any significant difference in the haemoglobin concentration, packed cell volume, or blood viscosity between the various groups.

Intermittent hypoxia has been shown to cause polycythaemia in animal studies, ${ }^{1}$ and hypoxia during sleep is thought to be an important determinant of the degree of secondary polycythaemia in patients with chronic obstructive airways disease. $^{2-4}$ Hypoxia increases the packed cel volume through two different mechanisms. Firstly, it causes a release of erythropoietin from the kidney, which then causes an increase in the red cell mass (a true polycythaemia). Secondly, hypoxia, both acute and chronic, can cause a contraction of the plasma volume (pseudopolycythaemia) through mechanisms which are poorly understood but possibly related to increased adrenergic activity and venoconstriction. ${ }^{5}$ In some patients both of these factors, increased red cell mass and reduced plasma volume, are present.

An increased packed cell volume, from whatever cause, is itself associated with an increased incidence of both ischaemic heart disease ${ }^{6-9}$ and cerebrovascular disease, ${ }^{9-11}$ thought to be due to its effect on the viscosity of blood. Several studies have shown that cerebral blood flow is reduced in patients with a high packed cell volume and can be improved by reducing the packed cell volume..$^{12}$ It is unfortunate that the authors do not mention the packed cell volume or haemoglobin concentration of their patients, even if only to state that there was no significant difference between the habitual snorers and the non-snorers, since they regard the intermittent hypoxia as the key to the increased incidence of arteriovascular disease in these patients. It would also be of interest to know if other risk factors such as enhanced coagulation or decreased fibrinolysis could be shown in the habitual snorers.

Department of Haematology

P YATES

Southmead Hospital,

ristol BS10 5NB

1 Moore-Gillon JC, Cameron IR. Right ventricular hypertrophy and polycythaemia in rats after intermittent exposure to hypoxia. Clin Sci 1985;69:595-9.

2 Stradling JR, Lane DJ. Development of secondary poly cythaemia in chronic airways obstruction. Thorax 1981;36: 321-5.

3 Flenley DC. Clinical hypoxia: causes, consequences, and correction. Lancet 1978; i:542-6.

4 Nocturnal Oxygen Therapy Trial Group. Continuous or nocturnal oxygen therapy in hypoxaemic chronic obstructive lung disease? Ann Intem Med 1980;93:391-8.

5 Isbister JP. Contracted plasma volume syndromes. International Joumal of Microcirculation: Clinical Experimentation 1984;3 93-108.

6 Burch GE, de Pasquale NP. The haematocrit in patients with myocardial infarction. JAMA 1962;180:63-5.

7 Lowe DGO, Drummond MM, Lorimer AR, et al. Relation between extent of coronary heart disease and blood viscosity. Angiology 1979;30:594-9.

8 Nicholaides AN, Bowers R, Horbourne T, Kidner PH, Besterman EM. Blood viscosity, red-cell flexibility, haematocrit and plasma fibrinogen in patients with angina. Lancet 1977 ;ii: plasm-5.

9 Cullen KJ, Stenhouse NS, Wearne KL. Raised haemoglobin and risk of cardiovascular disease. Lancet 1981;ii:1288-9.

10 Harrison MJG, Kendall BE, Pollock S, Marshall J. Effect of haematocrit on carotid stenosis and cerebral infarction. Lancet 1981;ii:114-5.

11 Kannel WB, Gordon T, Wolf PA, McNamara P. Haemoglobin and the risk of cerebral infarction: the Framingham study Stroke 1972;3:409-20.

12 Thomas DJ, Marshall J, Russell RWR, et al. Effect of haem tocrit on cerebral blood-flow in man. Lancet 1977;ii:941-3.

13 Humphrey PRD, Michael J, Pearson TC. Management of relative polycythaemia: studies of cerebral blood flow and viscosity. Br J Haematol 1980;46:427-33.

\section{Association between liberalisation of Scotland's liquor licensing laws and admissions for self poisoning}

SIR,-In our paper (6 December, p 1466) we did not seek to attribute the sharp and immediate increase in the percentage of patients taking alcohol with their overdose to changes in the Scottish licensing laws alone, as the percentage of women taking alcohol was increasing slowly before 1976 . Pace Drs S P Lockhart, J H Baron, and Stephen Platt (10 January, p 116), we still believe, however, that the sharp and immediate rise which occurred in the two years after the change in the law justified our suggestion that there was likely to be a direct relation between these two facts. Our clinical data on poisoned patients have been under consistent and detailed review over the past 17 years and we 